\title{
Nonparametric regression modelling of green sea turtle growth rates (southern Great Barrier Reef)
}

\author{
Colin Limpus, Milani Chaloupka*
}

Queensland Department of Environment, PO Box 155, Brisbane Albert Street, Queensland 4002, Australia

\begin{abstract}
Somatic growth rates recorded between 1974 and 1991 for green sea turtles Cheloma mydas resident in the southern Great Barrier Reef (sGBR) foraging grounds of the sGBR genetic stock were modelled using nonparametric regression. The sampling design in this long-term mark-recapture program was mixed longitudinal and included growth records for female and male turtles ranging between 39 and $116 \mathrm{~cm}$ CCL (curved carapace length). Distinct sex-specific growth patterns were found, adults displayed constant negligible growth while inter-annual variability in immature female growth attributable to major oceanographic events was evident. Females grew faster than the males from ca 62 to $65 \mathrm{~cm} \mathrm{CCL}$ with divergent growth patterns following distinct juvenile growth spurts. The expected female size-specific growth rate function was nonmonotonic, rising from recruitment size ( $>35 \mathrm{~cm} \mathrm{CCL)} \mathrm{to} \mathrm{maximum} \mathrm{growth} \mathrm{of} 2.1 \mathrm{~cm} \mathrm{yr}^{-1}$ at $\mathrm{ca} 60 \mathrm{~cm}$ CCL before declining to negligible growth approaching sexual maturity at ca 95 to $100 \mathrm{~cm}$ CCL. The male size-specific growth rate function was nonmonotonic rising from the same recruitment size to maximum growth of $2.2 \mathrm{~cm} \mathrm{yr}^{-1}$ at ca $63 \mathrm{~cm} \mathrm{CCL}$ before declining faster than females to negligible growth approaching sexual maturity at a signuficantly smaller size, $\leq 95 \mathrm{~cm}$ CCL. Assuming a post-hatchling pelagic phase of $5 \mathrm{yr}$, the mean age at sexual maturity for each sex was estimated at $\geq 40$ yr using numerical integration of the expected size-specific growth rate functions. Expected age-specific growth rate functions for each sex derved by numerical differentiation showed that the juvenile growth spurt for females resident in the sGBR foraging grounds occurs at around 9 yr at large sunce recruitment $(60 \mathrm{~cm} \mathrm{CCL,} \geq 14$ yr old) and for males at ca 11 yr at large $(63 \mathrm{~cm} \mathrm{CCL}, \geq 16$ yr old $)$. Juvenile growth spurts, sex-specific growth, slow size-specific growth rates, inter-annual growth variability of immatures and many decades to sexual maturity are growth characteristics for green sea turtles resident in the SGBR foraging grounds of the sGBR genetic stock
\end{abstract}

KEY WORDS: Somatic growth - Green sea turtles - Great Barrier Reef Nonparametric regression

\section{INTRODUCTION}

The green sea turtle Chelonia mydas is a threatened marine turtle species with a broad pantropical distribution and distinct regional population substructures (Bowen et al. 1992). The green turtle has been subject to a long history of extensive human exploitation for meat and egg harvests (Parsons 1962, Nietschmann 1979, Frazier 1980, Mortimer 1992). Green turtle stocks are in decline in many Indo-Pacific regions (Limpus 1993a, Horikoshi et al. 1994) with the northern Australian genetic stocks (see Norman et al. 1994) rep-

-Addressee for correspondence.

E-mail:m.chaloupka@mailbox.uq.edu.au resenting some of the few remaining stocks with seemingly viable breeding populations.

In northern Australian waters, greens have a low probability of being caught incidentally in prawn fishery trawls despite being abundant and they also have a low probability of drowning once caught (Poiner \& Harris 1996). While the green turtle is not seriously at risk from trawling it is nonetheless caught in large numbers in the northern prawn fishery due to the large fleet size and is also heavily harvested for meat in nearby Torres Strait (Harris et al. 1995), Papua New Guinea (Hirth \& Rohovit 1992) and Indonesian waters (Limpus 1994). Moreover, green turtle foraging grounds in coastal habitats are at risk globally from human settlement and coastal land development 
(National Research Council 1990). Clearly the green sea turtle is under threat globally and at increasing risk in northern Australian waters so that improved knowledge of this species is needed to ensure the long-term viability of various regional stocks.

We present a comprehensive statistical analysis of green turtle growth rates obtained from a long-term mark-recapture program (Limpus \& Reed 1985, Limpus 1992) of the southern Great Barrier Reef (sGBR) genetic stock (Norman et al. 1994) resident in sGBR foraging grounds (Limpus et al. 1992). Post-natal somatic growth for most species of sea turtle comprises separate compartments: (1) an epipelagic post-hatchling feeding phase and (2) a benthic feeding phase. This study considers only the benthic phase for green turtles ( $>35 \mathrm{~cm} \mathrm{CCL}$, curved carapace length, to sexually mature adults) resident in sGBR foraging grounds. Greens $<35 \mathrm{~cm}$ CCL have not been recorded from sGBR foraging grounds so the growth functions presented are not applicable to the as-yet unobserved epipelagic phase (ca 5 to $35 \mathrm{~cm}$ CCL). Nonetheless, the growth analysis presented here provides a basis for a better understanding of sea turtle growth dynamics, which is not well known (Chaloupka \& Musick 1997), and for modelling of green turtle population dynamics as shown by Chaloupka \& Limpus (1996b).

\section{METHODS AND MATERIALS}

Data set (green turtle growth rates). The data set comprised 1037 growth records for 537 green turtles (principally from the SGBR genetic stock) tagged with titanium tags in the sGBR feeding grounds between 1974 and 1991. All the rookeries in the sGBR comprise the same panmictic interbreeding stock and are distinct genetically from the northern Great Barrier Reef, Gulf of Carpentaria and Western Australian stocks (Norman et al. 1994). The data set included growth records for both female and male green turtles spanning the entire post-recruitment phase from 39 to $116 \mathrm{~cm} \mathrm{CCL}$, with $27 \%$ of the records derived from sexually mature individuals. The 537 individual turtles comprised 261 females and 276 males, providing 532 and 505 growth records respectively, with $41 \%$ of individuals recaptured 2 or more times. All size measurements were recorded as midline CCL (cm CCL) measured with a fibreglass tape marked in $0.1 \mathrm{~cm}$ intervals - instrumental measurement error is $\pm 0.05 \mathrm{~cm}$ but a full analysis of all sources of measurement error (observer, instrumental, calculation) is beyond the scope of this study. Further details of this long-term mark-recapture program can be found elsewhere (Limpus \& Reed 1985, Limpus 1992) while Chaloupka \& Musick (1997) provide an overview of the sampling and tagging protocols inherent in sea turtle markrecapture programs.

Capture-recapture profiles recorded for each turtle included the following: CCL at first capture and recaptures, sex and maturity determined from visual examination of the reproductive organs using laparoscopy (see Limpus \& Reed 1985), year of first capture and years at large since first capture or previous recapture Only turtles with recapture intervals $\geq 1$ yr were included to help minimise measurement error on growth rate estimation. Recapture intervals ranged from 1 to $12 \mathrm{yr}$ for females and 1 to $10 \mathrm{yr}$ for males, with the median recapture interval being 2 yr for both sexes. Absolute growth rates were derived from these capture-recapture profiles (Chaloupka \& Limpus 1997). Both negative and zero growth rates were included in the analysis since, as noted elsewhere (Chaloupka \& Limpus 1996a, Chaloupka \& Musick 1997), there is no valid reason to do otherwise.

Sampling design. Somatic growth is a complex timevarying demographic process comprising age, year and cohort effects (Chaloupka \& Musick 1997). Year effect is an environmental factor while the cohort effect is a genetic factor. Confounded time effects can result in biased growth estimates so analyses need to uncouple the time effects. This is not always possible due to limitations imposed by the mark-recapture sampling design and because of limitations in reliable aging of sea turtles. The implicit sampling design in this study was mixed longitudinal sampling (sampling with partial replacement) with $41 \%$ of individual green turtles recaptured 2 or more times. But because age was unknown, as in most sea turtle studies, the implicit sampling design here confounds year and cohort effects. A discussion of time-varying demographic sampling designs in relation to sea turtle studies is presented in Chaloupka \& Musick (1997).

Statistical modelling approach. The relationship between absolute growth rates recorded for each green turtle and specific growth rate predictors (covariates) was modelled statistically using a nonparametric regression approach known as generalized additive modelling (GAM; Hastie \& Tibshirani 1990). GAM enables robust analysis of regression models with both nonlinear covariate functional form and nonnormal error terms. The GAM regression model presented here used (1) an identity link since no other response tranformation was necessary, (2) a robust quasi-likelihood error function (Hastie \& Tibshirani 1990) to minimise any outlier effects on parameter estimates and (3) flexible cubic smoothing splines (Hastie \& Tibshirani 1990) to model the nonlinear functional relationship between the response and covariates. A quasi-likelihood error function is general, depending only on an empirical mean-variance relationship 
derived from the data itself, and is useful for accounting to some extent for correlated error inherent in mixed longitudinal data sets (McCullagh \& Nelder 1989).

The GAM fit summary used here comprises 2 parts: (1) an estimate of the contribution of each predictor to the overall model fit using $t$-ratio statistical inference and (2) an estimate of the nonlinearity for each continuous predictor (nonparametric term) using a nonparametric F-ratio test. The basis for using $t$ - and F-ratio inference in GAM modelling is well discussed elsewhere (Hastie \& Tibshirani 1990, Hastie 1993). Both summary parts are arranged into a tabular format for ease of reporting and interpretation. A more detailed outline of the GAM approach, rationale for its use in sea turtle growth modelling and the summary format used here was presented in Chaloupka \& Limpus (1997)

\section{RESULTS}

The GAM model comprised 1 response variable (absolute growth rates) and 5 potential growth factors (sex, maturity.group, year, mean.size, recapture.interval-see Table 1). The sex factor is self evident with the remaining 4 factors (maturity group, year, mean. size, recapture.interval) nested within sex to form 2 submodels (Fig 1). Maturity.group is the maturity status for each turtle (where 1 = immature, 2 = sexually mature adult; see Fig. 1a, e). Recall that maturity status was determined using laparoscopy (see 'Methods and materials'). Just because an individual was large did not necessarily mean that it was a mature adultequally, just because a turtle was less than mean adult size did not necessarily mean that it wasn't a sexually mature adult. Without laparoscopy the assignment of individuals to maturity classes based on size criteria would have been erroneous

Year is an estimate of the effective Julian year of the growth record and was included to account for the implicit time-dependent sampling design (Fig. 1b, f). The year effect is also a source of growth variability due to environmental factors but, because of the mixed longitudinal sampling design inherent in the current study, it is confounded with unknown cohort effects (see Chaloupka \& Musick 1997). Moreover, the year effect is imprecise here because not all growth records were for 1 and only 1 yr duration. While the minimum growth or recapture interval was $1 \mathrm{yr}$, the median recapture interval was 2 yr Therefore, the year effect was measured in this study with error of 2 yr, making assignment to a specific calendar year inaccurate.

Nonetheless, the year covariate as defined here is a useful proxy of the year effect and should be included in a model because it is a sampling design constraint inherent in all mark-recapture programs-it is simply an unavoidable part of any growth study that records growth over time (i.e. any longitudinal or mixed longitudinal sampling program).

Mean size is the arithmetic mean of CCL at first capture and CCL at subsequent recapture (see Fig 1C, g).

Table 1. Summary of GAM parameter estımates with quasi-likelihood error term and cublc smoothing splines fitted to green turtle growth rates nested within sex. The log-likelıhood ratio test for sex (female and male submodels below) $=(303.2-198.6)=$ 104.6 deviance on $(518.2-491.2)=27 \mathrm{df}$, $\operatorname{Prob}\left(\chi^{2}\right)<0.0001$ npar nonparametric (nonlinear) effects; df: degrees of freedom; ns: not significant; Prob $(F)$ based on npar df and residual deviance df. A significant npar $F$ means the covariate was nonlinear-if a linear model was used then it would have been concluded erroneously that the covariate functional relationship with the response was linear If the $t$-test for a covariate is not significant then the npar F-tost for nonlinearity is irrelevant

\begin{tabular}{|c|c|c|c|c|c|c|c|}
\hline \multirow[t]{2}{*}{ Parameter } & \multirow[t]{2}{*}{ Estimate } & \multirow{2}{*}{$\begin{array}{l}\text { Asymptotic } \\
\text { standard error }\end{array}$} & \multirow[t]{2}{*}{ t-ratio } & \multirow[t]{2}{*}{$\operatorname{Prob}(t)$} & \multicolumn{3}{|c|}{ Nonlinear effects (nonparametric) } \\
\hline & & & & & npar df & nраг $F$ & $\operatorname{Prob}(F)$ \\
\hline \multicolumn{8}{|l|}{ Female submodel } \\
\hline$($ constant) & -0.0294 & 0.7679 & -0.038 & ns & & & \\
\hline maturity.group & -0.4550 & 0.1268 & -3.587 & $\mathrm{p}<0.001$ & & & \\
\hline year & -0.0404 & 0.0089 & 4.492 & $p<0.001$ & 2.9 & 21.340 & $p<0.0001$ \\
\hline mean size & -0.0258 & 0.0024 & -10.768 & $p<0.001$ & 2.9 & 32.495 & $p<0.0001$ \\
\hline \multirow{2}{*}{ recapture interval } & 0.0451 & 0.0187 & 2.417 & $p<0.02$ & 3.0 & 1.673 & ns \\
\hline & \multicolumn{7}{|c|}{$\begin{array}{l}\text { Null deviance }=637.3, \text { null } \mathrm{df}=531, \text { residual deviance }=303.2, \text { residual } \mathrm{df}=518.2 \\
\text { quasi-lıkelıhood dispersion parameter }=0.482, \mathrm{R}^{2}=(637.3-303.2) / 637.3=0.52\end{array}$} \\
\hline \multicolumn{8}{|l|}{ Male submadel } \\
\hline$($ constant $)$ & 3.0036 & 0.6080 & 4.939 & $p<0.001$ & & & \\
\hline maturity.group & -0.6106 & 0.0923 & -6.615 & $p<0.001$ & & & \\
\hline year & 0.0071 & 0.0071 & 1.009 & ns & 2.9 & 7.450 & $p<0.0001$ \\
\hline mean size & -0.0289 & 0.0026 & -11.256 & $p<0.001$ & 2.9 & 51.822 & $p<0.0001$ \\
\hline recapture.interval & 0.0166 & 0.0146 & 1.139 & ns & 3.0 & 3.259 & $p<0.05$ \\
\hline & \multicolumn{7}{|c|}{$\begin{array}{l}\text { Null deviance }=685.5, \text { null } \mathrm{df}=504, \text { residual deviance }=198.6, \text { residual } \mathrm{df}=491.2 \\
\text { quasi-likelihood dispersion parameter }=0.316, \mathrm{R}^{2}=(685.5-198.6) / 685.5=0.71\end{array}$} \\
\hline
\end{tabular}



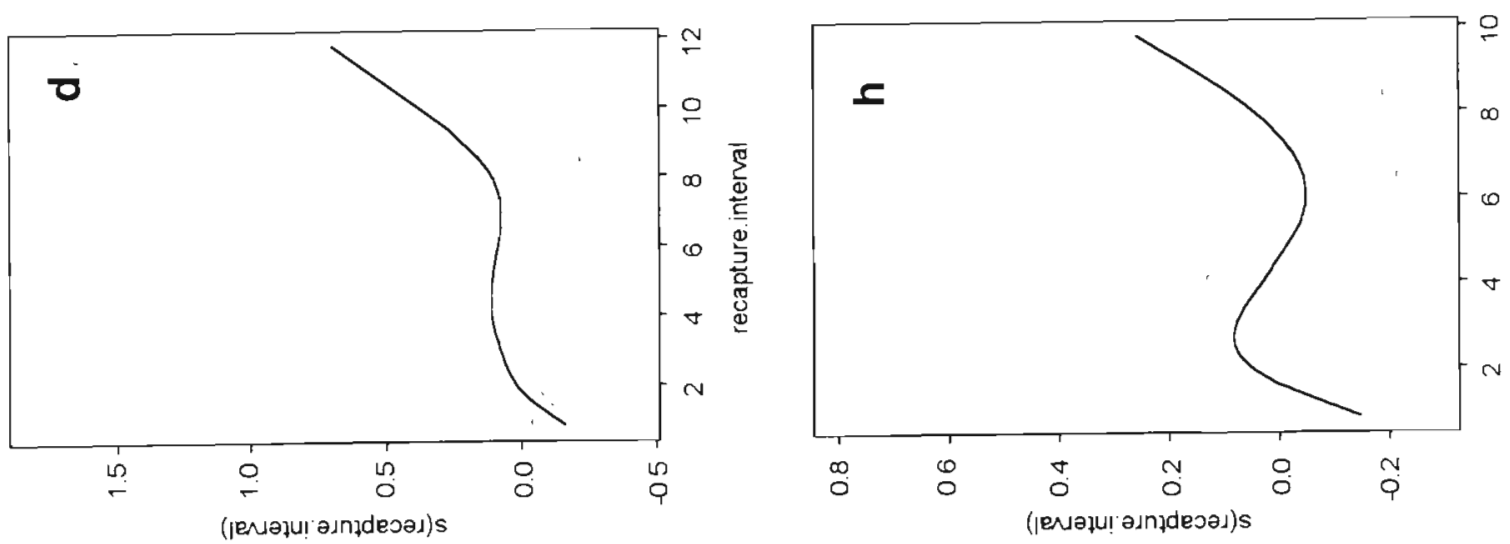

$\Xi 5 \overrightarrow{0} \ddot{0}$

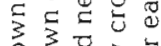

过星司司

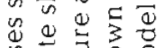

음요용

$2 \int^{\pi} \frac{\pi}{\pi} \Sigma$

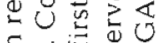

舟它志

更过

Q

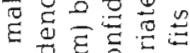

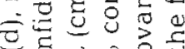



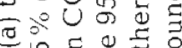

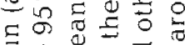
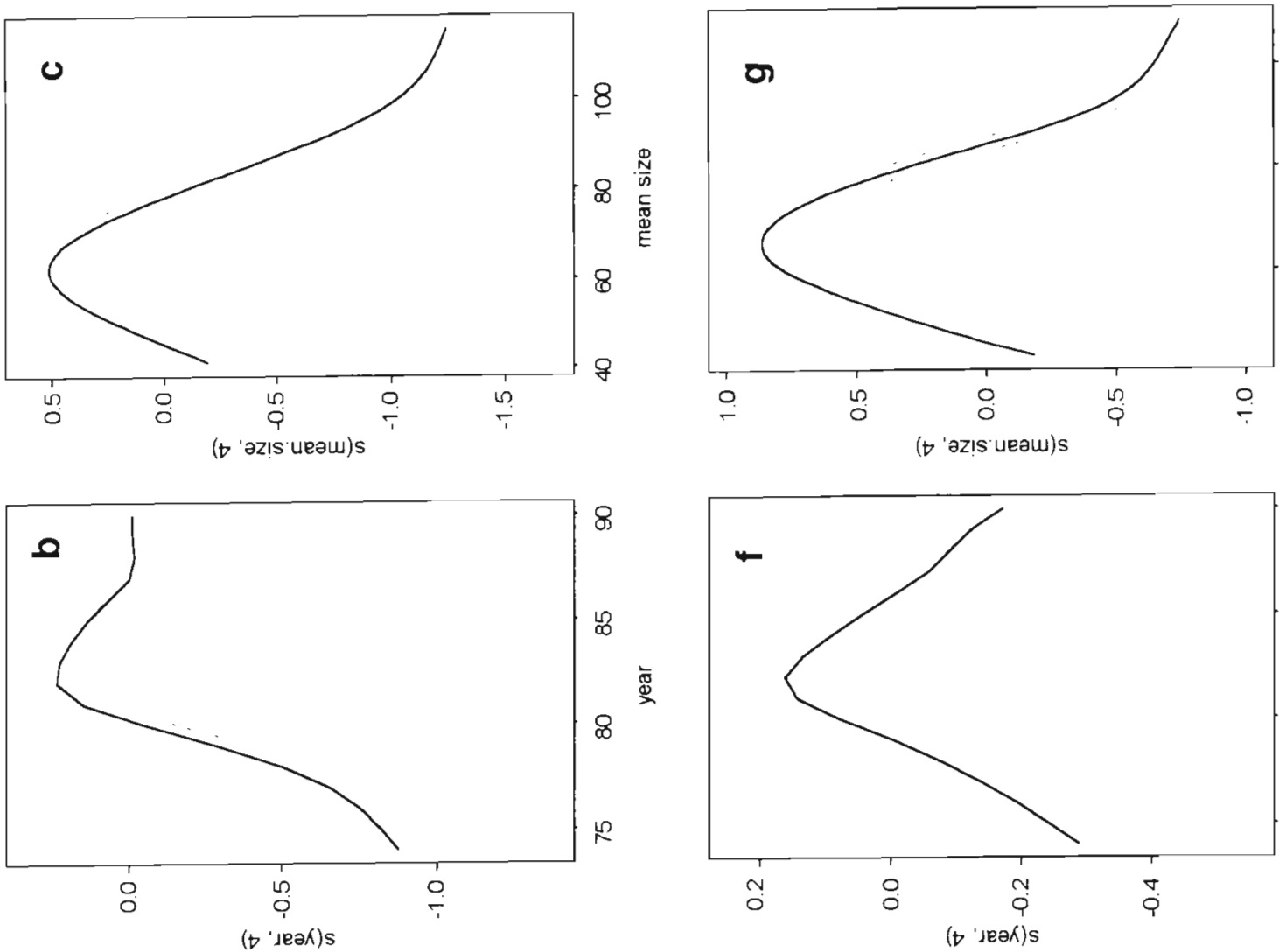



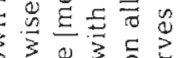

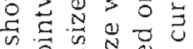



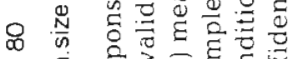
ॠ

I 5 is

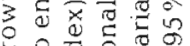

与ㄴ.

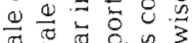

in 203

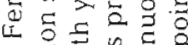

$\rightarrow \vec{U} 3 \overrightarrow{0} 0$

$5 \stackrel{0}{1} 00$

영

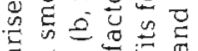

$\infty \quad$ 品

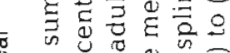

- $00 \stackrel{0}{0} 0$

8



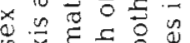

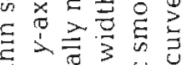

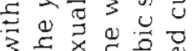

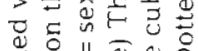

तथ 0

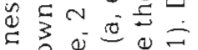

$\exists$ 도

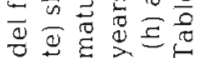

马े

온 $\Xi 2$

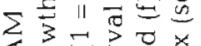

\& $=20$

흑응



은

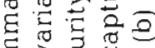

马西导

तु

造远

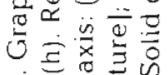

- $8 x$ 夜

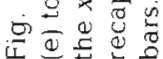


Mean size is the appropriate size metric for indexing size-specific growth assuming that growth is locally linear within a sampling interval (see Chaloupka \& Limpus 1997). This assumption is reasonable if short sampling intervals are used, however, in long-term mark-recapture programs sampling intervals usually span a considerable time range. For instance, in the current study sampling intervals ranged from 1 to $12 \mathrm{yr}$ (median = $2 \mathrm{yr}$ ) so that this factor (recapture.interval) has also been included in the model to account for potential bias due to variable sampling interval (see Fig. 1d, h).

The GAM regression analysis found that both maturity.group and mean. size nested within sex have a significant effect on green turtle growth rates (Table 1). Immature green turtles, irrespective of sex, grew much faster than mature adults, bearing in mind that many adults (assessed by laparoscopy) are no larger than many large immatures (Table 1, Fig. 1a, e). Mean.size was not only a significant factor affecting sex-specific growth rates but was also distinctly nonlinear for either sex (Table 1, Fig. 1c, g). The female growth submodel was significantly different from the male submodel (Table 1) inferring distinct sex-specific growth characteristics (Table 1, loglikelihood ratio test $=104.6, \mathrm{df}=27, \mathrm{p}<0.0001)$. The female size-specific growth rate function (Fig. 1c) is distinct from the male growth function (Fig. 1g) with the females diverging significantly from males after reaching maximum growth rates around 60 to $65 \mathrm{~cm}$ CCL. Overall, absolute growth rates for green sea turtles in the sGBR genetic stock are sex, size and maturity status dependent. Moreover, both female and male adult green turtles displayed constant negligible growth following the onset of sexual maturity around 95 to $100 \mathrm{~cm}$ CCL (Fig. 2). Mature adult males also displayed significantly slower growth relative to immature males than was evident for mature adult females relative to immature females (cf. maturity.group parameter estimates for each sex in Table 1).

Year and recapture.interval were also found to be important factors affecting female growth rates (Table 1, Fig. 1b, d, respectively). The year effect indicates significant inter-annual growth variation, inferring an environmental influence on immature female growth rates since adult females hardly grow at all. For female growth the year effect was distinctly nonlinear, suggesting an abrupt and somewhat temporary increase in growth rates during the early 1980s (Table 1, Fig. 1b) - a period coincidental with the strongest El Niño-Southern Oscillation (ENSO) event this century (see Wang 1995). On the other hand, neither year nor recapture.interval were factors affecting male growth (Table 1) despite the year effect also displaying an abrupt but temporary functional form (Fig. 1f)

The GAM nonparametric regression model for either sex was a good fit to the sex-specific growth data, evident in a small residual deviance relative to residual degrees of freedom (Table 1), acceptable nonparametric $R^{2}$ values (Table 1 ) and no aberrant residual behavioural patterns assessed using data visualization (see Cleveland 1993). Both robust quasi-likelihood dispersion parameters (Table 1) suggest that arbitrary error functions were warranted (see McCullagh \& Nelder 1989). However, the $\mathrm{R}^{2}=0.52$ for females (Table 1) indicated that while the GAM model accounted for $52 \%$ of the growth variance, female green turtles still displayed significant individual growth variation when compared with male growth where $71 \%$ of the variance was accounted for (Table 1). In other words, the GAM model explains male growth much better than it explains female growth. Female growth was clearly more variable than male growth and apparently influenced by environmental factors. 
The advantage of using GAM rather than a linear parametric model is quite apparent when the results of both approaches are compared. For instance, a linear parametric model (GLM; see Draper \& Smith 1981) of female growth including quadratic polynomial year and mean.size functions in addition to all other covariates only accounted for $39 \%$ of the variance compared to the GAM fit of $52 \%$ shown in Table 1. A similar GLM model for male growth accounted for $58 \%$ of the variance compared to the GAM fit of $71 \%$ in Table 1. Yet the GLM models (GLMs) found a significant year effect for male growth, an effect that was discounted by the GAM models (GAMs) when the correct nonlinear functional form for the covariates was used. Moreover, the GLMs did not find the significant difference between immature and mature female growth that was clearly evident in the data using data visualization (Cleveland 1993) and supported by the GAMs.

Overall, the GAMs were good fits while the GLMs were poor fits to the green turtle growth data. It seems that statistical modelling of sea turtle growth data can be more effective using nonparametric regression models that incorporate nonlinear functional form, non-normal error structures and robust parameter estimation. Nonetheless, it is important to recall that since the sampling design was mixed longitudinal with unknown age, no growth model (GAM or any other) can account adequately for bias due to confounded year and cohort effects. Therefore, while a strong year effect was evident for immature females, it remains confounded with cohort effects limiting the power of the inference about environmental affects on growth rates.

Covariate function plots for a GAM fit (Fig. 1) are centred on the response scale by subtracting a weighted mean to ensure valid pointwise $95 \%$ confidence bands (Hastie \& Tibshirani 1990). While essential for analytical purposes, centred plots are more difficult for the user to decode on the original response (i.e. growth rate) scale. To aid interpretation of the size-specific growth functions the predicted model values were replotted on the uncentred growth rate scale for each sex with cubic B-spline smooths superimposed to highlight the underlying nonlinear functions (Fig. 2). Note then that Fig. 2 is simply the curves in Fig. 1c, g, replotted on the growth rate scale rather than the centred GAM scale. Pointwise confidence bands are no longer valid in this format but the fitted model values provide a clear indication of the expected growth variability around the smoothed sex-specific growth functions in Fig. 2.

Distinct sex-specific growth patterns are clearly evident in Figs. 1c, g \& 2 with immature female green turtles growing faster than immature males once they had both reached a size around 60 to $65 \mathrm{~cm}$ CCL (Fig. 2).
The estimated size-specific growth rate function for females was nonmonotonic, rising rapidly from a benthic phase recruitment size ( $>35 \mathrm{~cm} \mathrm{CCL}$ ) to a maximum growth rate of $2.1 \mathrm{~cm} \mathrm{yr}^{-1}$ at about 60 to $62 \mathrm{~cm}$ $\mathrm{CCL}$ before declining to negligible growth approaching sexual maturity at a size approaching 95 to $100 \mathrm{~cm}$ $\mathrm{CCL}$. The estimated size-specific growth rate function for males was nonmonotonic, rising from the same recruitment size to maximum growth of $2.2 \mathrm{~cm} \mathrm{yr}^{-1}$ about 62 to $65 \mathrm{~cm} \mathrm{CCL}$ before declining faster than females to negligible growth approaching sexual maturity at a smaller size, $\leq 95 \mathrm{~cm}$ CCL. The growth rate functions (Fig. 2) are monophasic functions (see Chaloupka \& Musick 1997) displaying a single growth cycle with a juvenile growth spurt for either sex ca 60 to $65 \mathrm{~cm} \mathrm{CCL}$ and are significantly different from each other (see Table 1).

The expected size-specific growth rate function for each sex represented by cubic B-splines (see Fig. 2 and repeated for convenience in Fig. 3a, d) were integrated numerically with respect to time (age estimate) using a finite difference equation and the Runge-Kutta integration method (see Gerald \& Wheatley 1994 for details). Recall then that the size-specific functions in Fig. 2 (repeated in Fig. 3 a, d) are the predicted results of the GAM model summarised in Table 1 The resulting monotone growth function for each sex (i.e. an I-spline; see Ramsay 1988) is then an empirical estimate of the expected size-at-age growth function where age is years at large since recruitment into the benthic developmental phase at a size $>35 \mathrm{~cm} \mathrm{CCL}$ (see Fig. 3c, f). We refer to years at large since recruitment rather than age because we are modelling only the benthic growth phase ( $35 \mathrm{~cm} \mathrm{CCL}$ to mature adult) without knowing the actual age of turtles since birth at $5 \mathrm{~cm}$. Therefore, age (years at large since birth) is the sum of the epipelagic developmental phase duration plus years at large since recruitment into the benthic phase. Years at large since recruitment is then only an estimate of minimum age because we do not yet have a conclusive estimate of the duration of the epipelagic developmental phase for this stock (see Limpus et al. 1994).

Note that these age-specific growth functions (Fig. 3) for each sex (1) were derived from the GAM model conditioning on the covariates summarised in Table 1 and (2) were then derived by numerical integration of the curves in Fig. 2 without recourse to the size-based growth analogues that were discussed at some length in Chaloupka \& Musick (1997).

\section{DISCUSSION}

Somatic growth of wild stock green sea turtles is not well known (Chaloupka \& Musick 1997). While there 

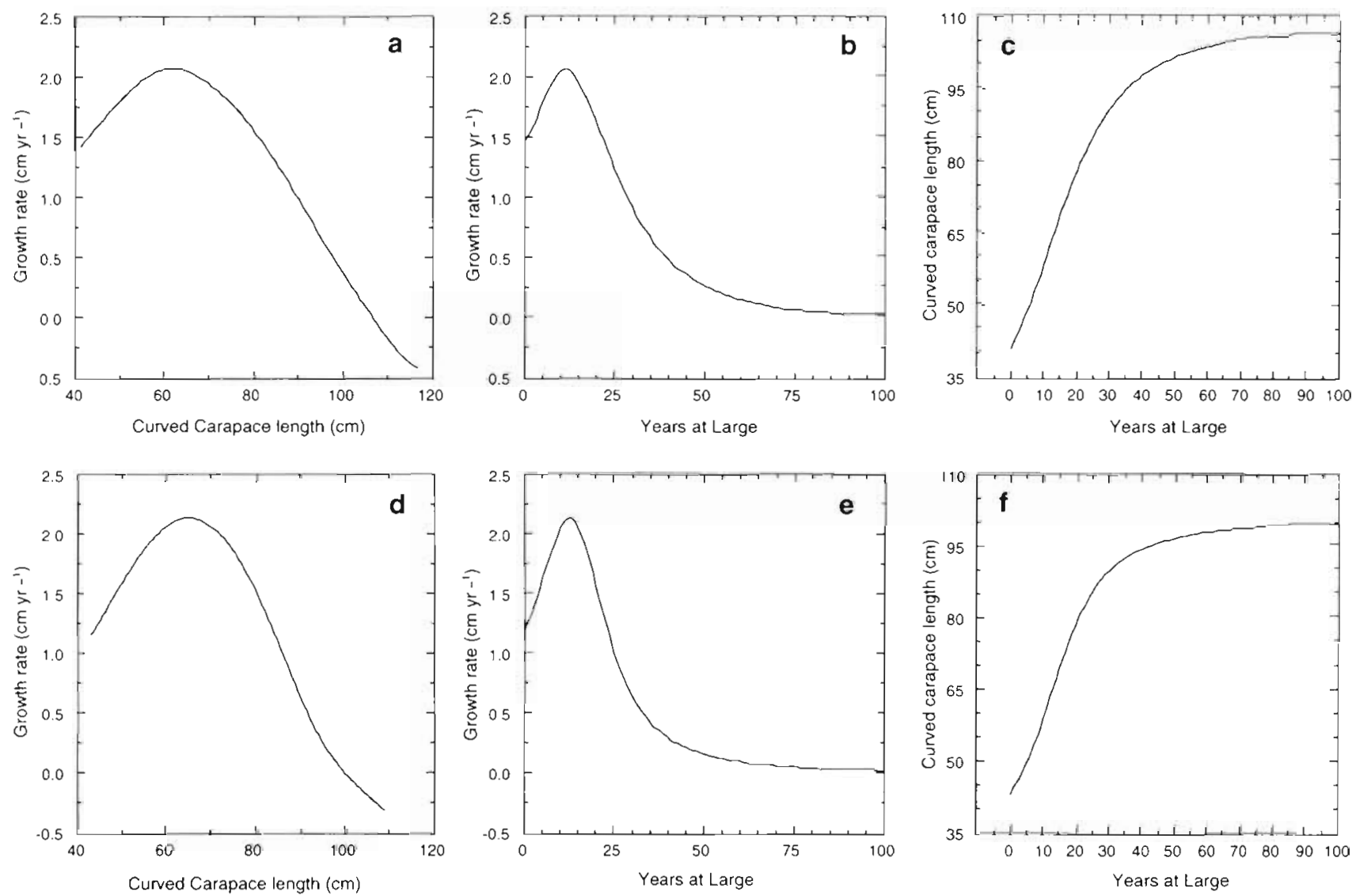

Fig. 3. Chelonia mydas. Estimated age- and size-specific growth functions for each sex derived from the GAM model fit that was conditioned on all the covarrates (Table 1). Female growth functions shown in (a) to (c); corresponding male functions in (d) to (f) $(\mathrm{a}, \mathrm{d})$ The size-specific growth rate functions derived using cubic B-spline fit to the GAM predicted values are reproduced (see Fig. 2). Those functions were integrated numerically to give the expected size-at-age (age = years at large) functions for (c) females and (f) males, conditioned on all the covariates in the GAM model. The expected size-at-age spline functions (c) and (f) were then differentiated numerically with respect to time to give the expected age-specific growth rate functions shown for (b) females and (e) males. 95\% confidence curves are not included because the functions (c, f) are arbitrary smooth functions derived from other smooth functions $(a, d)$ with no feasible way to estimate valid pointwise standard errors

are several compilations of growth rates of green turtles reared in captivity (Zug et al. 1986, GodinezDominguez et al. 1993) these data bear little resemblance to growth observed in wild stocks. For instance, green turtle growth in captivity is generally much faster than growth in wild stocks (Bjorndal 1985) - that is, captive reared sea turtles reach a given carapace size or maturity at an earlier time. Moreover, captivity studies involve longitudinal sampling with known age, resulting in confounded age and year effects. On the other hand, wild stock growth studies invariably involve mixed longitudinal sampling with unknown age, confounding cohort and year effects. The sampling designs implicit in captive and wild stock growth studies lead to different sampling biases for time-dependent demographic processes such as growth (Chaloupka \& Musick 1997) and so are not strictly comparable. Hence there is no substitute for growth studies based on wild sea turtle stocks, especially where these data are then used in population dynamic models for evaluating conservation policy options.

The green turtles considered in the current study were from the sGBR genetic stock (Norman et al. 1994) resident in the sGBR foraging grounds (Limpus et al 1992). Rookeries for this stock occur on most coral cays in the sGBR region. The green turtles in this sample spanned the entire post-pelagic phase ranging from 39 to $116 \mathrm{~cm}$ CCL in size, with both sex and maturity confirmed using laparoscopy (see Limpus \& Reed 1985). Therefore the size- and age-specific growth functions developed here for green turtles resident in sGBR waters are the first substantive somatic growth functions presented for any wild sea turtle stock for the entire post-pelagic ontogenetic phase (see Chaloupka \& Musick 1997). 


\section{Size-specific growth rate functions}

The usual approach adopted for analysis of sea turtle growth with unknown age has been size-based analogues of age-based parametric growth curves (Chaloupka \& Musick 1997). This approach has several shortcomings: (1) a parametric function (e.g. von Bertalanffy, logistic, Gompertz) must be arbitrarily pre-specified, (2) factors affecting growth such as maturity status, sampling design constraints and sex are not taken into account when deriving the sizespecific growth function and (3) the growth parameters derived from such analogues are not equivalent to age-based parameters and so cannot be substituted into age-based functions to derive size-at-age curves, despite this being a common practice (Chaloupka \& Musick 1997).

The 2-stage modelling approach of Chaloupka \& Limpus (1996a) adopted in the current study comprised: (1) a nonparametric statistical model of growth rates for unknown age sea turtles to derive the expected size-specific growth rate function for each sex conditioned on informative covariates and sampling design constraints, followed by (2) numerical integration of the size-specific growth rate functions to derive an estimate of the expected size-at-age growth functions for each sex. This 2-stage approach, while analytically demanding, is more likely to help unravel the interactions involved in the complex growth dynamics of sea turtles.

The statistical growth rate modelling in the current study found distinct nonmonotonic size-specific growth rate patterns for each sex (Table 1, Fig. 2). The distinct growth pattern with a single growth spurt (monophasic; see Chaloupka \& Musick 1997) for either juvenile female or male greens at around 60 to $65 \mathrm{~cm}$ CCL (see Fig. 2) is characteristic of this sGBR stock. A similar GAM modelling approach was used by Chaloupka \& Limpus (1997) to analyse somatic growth rates for hawksbill turtles also resident in sGBR waters. They also found nonmonotonic growth patterns with a single juvenile growth spurt around $60 \mathrm{~cm}$ CCL and slow immature growth rates, suggesting that these might be growth features characteristic of sea turtle species from sGBR waters.

\section{Sex-specific growth}

The female and male green size-specific growth functions in the current study were found to be statistically different, with large juvenile females growing faster at all sizes $>60 \mathrm{~cm}$ CCL than comparably sized males (Table 1, Fig. 2), implying significant sexual dimorphism in size at maturity. Chaloupka \& Limpus
(1997) also found sex-specific growth rate functions for hawksbill turtles resident in sGBR waters.

Sex-specific growth has not been recorded previously for any other stocks of green sea turtles. Yet adult size dimorphism is well known for breeding green sea turtles (Limpus 1993b). The sex-specific growth functions (Fig. 2) indicate that mature male green turtles from the sGBR genetic stock resident in SGBR foraging grounds are smaller on average than mature females. Mean breeding size for male sGBR genetic stock turtles resident in SGBR foraging grounds was estimated at $98 \mathrm{~cm}$ CCL with mean female breeding size estimated at $103 \mathrm{~cm}$ CCL (Limpus \& Reed 1985). Numerical integration of the growth functions shown in Fig. 3 gives mean adult size estimates consistent with these empirical estimates of mean breeding size for female and male green sea turtles from the sGBR stock.

The only previous statistical analysis of growth rates in a wild green turtle stock was presented by Bolten et al. (1992) using a linear regression model. They found that growth rates of immature green turtles restricted to a developmental habitat in the Bahamas displayed a monotonic and linear decreasing function of size for the observed size range $(25$ to $70 \mathrm{~cm}$ straight carapace length, SCL). They concluded that there was no sexspecific difference in mean growth rates but the female and male subgroups were nonequivalent due to variation in sex ratios among size classes and so are not strictly comparable-males were disproportionately smaller than females, indicative of either a cohort effect or that males in fact grew more slowly than females at the same size

\section{Environmental effects on growth}

A significant environmental influence on immature females growth rates was found in this study (Table 1 , Fig. 1b) that has not been reported elsewhere for any other sea turtle species. It seems there was an abrupt but temporary increase in immature female growth rates during the early 1980 s coincident with the strongest El Niño-Southern Oscillation (ENSO) event this century (Wang 1995). The physiological mechanism underlying this environmental effect is unknown at this stage but would seem most likely to be a function of nutrition and reproductive ecology. Limpus \& Nicholls (1994) have shown using laparoscopy that the proportion of female green turtles in the sGBR preparing to breed in a given year is a delayed response to the onset of ENSO events, which are themselves a function of sea surface temperature anomalies. This functional relationship between acceleration of juvenile growth rates, proportion of breeding females and the onset of ENSO events has been incorporated into a 
stochastic simulation model of sGBR green turtle population dynamics (see Chaloupka \& Limpus 1996b)

Nonetheless, caution in interpreting the apparent environmental affect is warranted. The year effect on growth suggested by the GAM model is only a proxy measure of all the environmental influences actually experienced by the green turtles in the sGBR foraging grounds. Also the timing of the year effect is imprecise because of sampling error due to the variable recapture intervals. Only if all recapture intervals were of 1 yr duration would this then not be an issue, but recapture intervals in such studies invariably span many years because of field sampling logistics. Recapture intervals in the current study ranged from 1 to $12 \mathrm{yr}$ with a median recapture interval of $2 \mathrm{yr}$. The observed year effect (Table 1, Fig. 1b) therefore comprises variability due to measurement error in addition to environmentally induced variability. Moreover, the year effect is also confounded with cohort effects due to sampling design constraints inherent in a mixed longitudinal sample with unknown age further making it difficult to draw strong inferences about environmental effects.

Given the 2 issues of confounded cohort effects and imprecise year effect coding (see 'Methods and materials'), only a weak form of inference about environmental effects is possible-an environmental effect on immature female growth rates was evident but inconclusive due to the study limitations. Conclusive inference about environmental effects on sea turtle somatic growth will only be possible when (1) reliable age estimates for individual green sea turtles and (2) a large data set of individual growth records estimating growth rates for 1 and only 1 yr duration are available. Further studies of green turtle stocks are required to develop better insight into the complexity of environmental effects on sea turtle somatic growth rates.

\section{Geographical growth patterns}

The current study found distinct nonmonotonic sizespecific growth patterns for either sex for the SGBR green turtle stock (Fig. 1c, g). Several studies (Frazer \& Ehrhart 1985, Bjorndal \& Bolten 1988, Boulon \& Frazer 1990, Bjorndal et al. 1995) have proposed or implied that green turtle stocks resident in western AtlanticCaribbean waters display monotonic decreasing sizespecific growth rates implying no growth spurts. Yet Ehrhardt \& Witham (1992) found a nonmonotonic agespecific growth rate pattern with a growth spurt estimated at 10 to $11 \mathrm{yr}$ of age for a sample of immature head-started (known age) green turtles from the same region. Several other studies of wild stock green sea turtle growth have also found nonmonotonic size-spe- cific growth patterns (see Chaloupka \& Musick 1997). For instance, Collazo et al. (1992) found nonmonotonic growth for wild stock immature greens resident in Puerto Rican waters as did Green (1993) for immature wild stock greens from the Eastern Pacific (Galapagos Archipelago).

While there are a number of sampling protocol and statistical concerns with all these sea turtle growth studies (see Chaloupka \& Musick 1997) it would seem that a nonmonotonic size-or age-specific growth rate pattern is a characteristic observed in many green sea turtle stocks. If this is so, then such stocks display juvenile or mid-adolescent growth spurts possibly indicative of a significant ontogenetic shift associated with developmental migrations or dietary changes.

There also appear to be significant regional differences in the magnitude of immature growth rates. Size-specific growth rates for immature sGBR green turtle stock recorded from the current study are slower than those recorded for stocks from western AtlanticCaribbean waters, irrespective of whether monotonic (Frazer \& Ehrhart 1985, Boulon \& Frazer 1990, Bjorndal et al. 1995) or nonmonotonic (Collazo et al. 1992) growth rates were implied. For instance, Boulon \& Frazer (1990) found a mean growth rate for immature greens in US Virgin Island waters of $4.8 \mathrm{~cm} \mathrm{SCL} \mathrm{yr}^{-1}$ $(\mathrm{SE}=0.46)$ while Collazo et al. (1992) for a similar size range found a mean growth rate in Puerto Rican waters of $5.1 \mathrm{~cm} \mathrm{SCL} \mathrm{yr}^{-1}$ ( $\mathrm{SE}=0.83$ ). On the other hand, the mean growth rate for a comparable size range of immature greens in the current study (sGBR) was $1.7 \mathrm{~cm} \mathrm{CCL} \mathrm{yr}^{-1}$ (SE $=0.03$ ).

Balazs et al. (1994) also found slow growth (mean = $1.9 \mathrm{~cm} \mathrm{SCL} \mathrm{yr}^{-1}, \mathrm{SE}=0.13$ ) for immature greens resident in southern Hawaiian waters while Green (1993) recorded even slower growth rates for immature green turtles from the Galapagos Archipelago. Even allowing for transformation of SCL to CCL growth values, limited data sets and stock-specific mature adult size it seems that immature green turtles grow much slower in the Western, Central and Eastern Pacific regions than in western Atlantic-Caribbean waters (see also Green 1993). These general growth patterns are also consistent with the broad phylogenetically derived population substructures proposed by Bowen et al. (1992) for green sea turtles

Geographical differences in immature growth rates might also explain why mature female greens in the Pacific Ocean are apparently smaller than greens nesting for instance at rookeries in the western AtlanticCaribbean and southwestern Indian Ocean (van Buskirk \& Crowder 1994). Whether these inter-regional differences in immature growth rates are real is inconclusive for the moment since most green turtle data sets are too small for comparative analysis. On the 
other hand, adult green turtle growth is consistently recorded across regions as either negligible or perhaps having ceased altogether. For instance, Carr \& Goodman (1970) found that female greens nesting at Tortuguero (Costa Rica) grew at $<0.4 \mathrm{~cm} \mathrm{SCL} \mathrm{yr}{ }^{-1}$. The current study for the sGBR genetic stock found mature adult female growth rates of $0.12 \mathrm{~cm} \mathrm{yr}^{-1}(\mathrm{SE}=0.04)$ at 100 to $105 \mathrm{~cm} \mathrm{CCL}$ and for mature adult males of $0.07 \mathrm{~cm} \mathrm{yr}^{-1}(\mathrm{SE}=0.02)$ at 95 to $99 \mathrm{~cm} \mathrm{CCL}$. Adult male or female somatic growth is clearly negligible once sexual maturity is reached at some size around 95 to $100 \mathrm{~cm} \mathrm{CCL}$ for the sGBR genetic stock (see Fig. 2).

\section{Expected size-at-age function}

The size-specific growth functions for SGBR genetic stock (Fig. 3a, d) were numerically integrated to yield expected size-at-age growth functions (Fig. 3c, f) useful for trying to estimate sex-specific age at adult maturity or for modelling population dynamics. Chaloupka \& Limpus (1996a) fitted a system of Weibull-type growth equations to similar expected size-at-age functions represented by the monotone splines in Fig. 3c, $f$ (a description of this system of nonlinear equations will be presented elsewhere although the single equation form is given in Chaloupka \& Musick 1997). They estimated that green turtles from this stock increase in size from recruitment size (mean $=44.1 \mathrm{~cm} \mathrm{CCL}, \mathrm{SE}=0.61$; Limpus unpubl. data) to an asymptote (mean adult size) of $106 \mathrm{~cm} \mathrm{CCL}$ for females and $99 \mathrm{~cm} \mathrm{CCL} \mathrm{for}$ males. Taking these estimates in conjunction with Fig. 3c, $\mathrm{f}$, suggests that the estimated mean age of breeding females or males in the sGBR green turtle stock is $\geq 75 \mathrm{yr}$ at large since recruitment, which is also a minimum estimate of mean life expectancy since green turtle growth is negligible or ceased by this age or size. These age estimates for mean adult size must not be confused with estimates of mean age at sexual maturity or first breeding, which is reached at a smaller size (and hence younger age) than the mean breeding size inferred by using the estimated size-at-age asymptotes (see discussion below).

\section{Age-specific growth rate function}

The estimated size-at-age growth functions (Fig. 3c, f) presented in the current study were also differentiated numerically with respect to time to yield age-specific growth rate functions (Fig. 3b, e), which suggest that the observed juvenile growth spurt for females in the sGBR stock occurs about 9 to $10 \mathrm{yr}$ at large $(60 \mathrm{~cm}$ $\mathrm{CCL})$ and about 11 to $12 \mathrm{yr}$ at large $(63 \mathrm{~cm} \mathrm{CCL})$ for males. Ehrhardt \& Witham (1992) found that a juvenile growth spurt occurred around 10 to 11 yr of age for their head-started (known age) immature green turtle stock in the Western Atlantic

Assuming that the unobserved post-hatchling pelagic phase for the sGBR stock is $\geq 5$ yr (see Limpus et al. 1994) then it is estimated that the female juvenile growth spurt occurs around $\geq 14$ yr of age while the male juvenile growth spurt occurs around $\geq 16$ yr of age. Growth slows rapidly following the juvenile or mid-adolescent growth spurt and hence turtles from this SGBR stock take many years to reach sexual maturity.

\section{Age at maturity estimation}

It is common practice to use somatic growth functions (size-at-age curve) to estimate mean age at sexual maturity. The difficulty in using growth functions for this purpose is the lack of conclusive growth criteria to indicate onset of sexual maturity. Minimum or mean female nesting size are commonly used criteria that assume amongst many things that growth is not sexspecific

For instance, Ehrhardt \& Witham (1992) fitted a parametric growth function to a small sample of immature green turtles and suggested that sexual maturity was reached at 19 yr based on the minimum nesting female size criterion. But it is doubtful whether the minimum nesting size criterion is valid, because large mature adults tend also to have more rapid growth and development and therefore reach maturity at a younger age, resulting in an anomalous mean age at maturity estimate (see Frazer \& Ehrhart 1985). Moreover, the age at maturity estimate proposed by Ehrhardt \& Witham (1992) corresponds with turtles still growing at close to estimated maximum growth rates indicating that turtles in that stock had not reached anywhere near sexual maturity by $19 \mathrm{yr}$ - sexually mature green sea turtles display negligible growth (Carr \& Goodman 1970, Limpus 1993b, this study). The mean nesting size criterion applied to the growth functions presented by Ehrhardt \& Witham (1992) suggests that an estimate of mean age at maturity approaching 40 yr might be far more reasonable.

But whether the mean nesting size criterion is itself a valid estimate of onset of sexual maturity is also questionable. However, without reliable estimates of sizeor age-specific maturity rates it is not possible to resolve this issue. There are no explicit size- or agespecific maturity rate functions for green sea turtles but the basis for such estimates exist using laparoscopy and the reproductive and maturity status scoring criteria of Limpus (1992). Nonetheless, Limpus \& Reed (1985) and Limpus et al. (1994) presented quasi-size- 
specific maturity functions based on $5 \mathrm{~cm}$ CCL size classes, indicating that the mean transition from pubescent immature to sexually mature adult status occurs around 90 to $95 \mathrm{~cm}$ CCL for the sGBR green stock (i.e. $50 \%$ of 90 to $95 \mathrm{~cm}$ CCL turtles were classified as mature adults using laparoscopy).

Without explicit sex-specific maturity functions it is difficult to estimate with any reliability the mean age at sexual maturity for the current study although the turtles displayed negligible growth by $\leq 95 \mathrm{~cm}$ CCL (ca 35 yr at large) for either sex, implying this as a plausible size threshold to be reached prior to onset of sexual maturity (see Fig. 3a, b, d, e). The onset of negligible growth rates by $95 \mathrm{~cm}$ CCL is consistent with the crude maturity rate estimates proposed by Limpus \& Reed (1985) and Limpus et al. (1994) for the same genetic stock. Given these considerations it would seem reasonable to conclude that the mean age at sexual maturity would be $\geq 40$ yr for the sGBR stock -35 yr at large plus say $\geq 5$ yr as a reasonable crude estimate for the epipelagic phase duration (see Limpus et al. 1994 for recapture of immature greens marked as hatchlings in the sGBR).

It seems apparent then that maturity estimates for either male or female greens in the sGBR would be grossly overestimated using a mean breeding size criterion rather than a negligible growth criterion or, preferably, an explicit maturity rate function. Nonetheless, green sea turtles in the sGBR stock clearly grow slowly and hence take many decades to reach sexual maturity as proposed by Limpus (1993b).

Acknowledgements. This work was funded in part by grants from the Australian Nature Conservation Agency, Australian Department of Science (Marine Science and Technology) and the Great Barrier Reef Marine Park Authority. Field assistance was provided by S. Allen, D. Walter, A. Fleay, P. Reed, E. Gyuris, D. Reimer and numerous volunteer assistants. We thank K. Bjorndal, A. Meylan, J. Miller and the anonymous referees for helpful comments on the manuscript.

\section{LITERATURE CITED}

Balazs GH, Dudley WC, Hallacher LE, Coney JP, Koga SK (1994) Ecology and cultural significance of sea turtles at Punalu'u, Hawaii. In: Bjorndal KA, Bolten AB, Johnson DA, Eliazar PJ (eds) Proceedings of the Fourteenth Annual Symposium on Sea Turtle Biology and Conservation. NOAA Tech Memo NMFS-SEFSC-351:10-13

Bjorndal KA (1985) Nutritional ecology of sea turtles. Copeia 1985:736-751

Bjorndal KA, Bolten AB (1988) Growth rates of immature green turtles, Chelonia mydas, on feeding grounds in the southern Bahamas. Copeia 1988:555-564

Bjorndal KA, Bolten AB, Coan AL, Kleıber P (1995) Estimation of green turtle (Chelonia mydas) growth rates from length-frequency analysis. Copeia 1995:71-77

Bolten AB, Bjorndal KA, Grumbles JS, Owens DW (1992) Sex ratio and sex-specific growth rates in immature green tur- tles. Chelonia mydas, in the southern Bahamas. Copeia 1992:1098-1103

Boulon RH, Frazer NB (1990) Growth of wild juvenile Caribbean green turtles, Chelonia mydas. J Herpetol 24:441-445

Bowen BW, Meylan AB, Ross JP, Limpus C J, Balazs GH, Avise JC (1992) Global population structure and natural history of the green turtle (Chelonia mydas) in terms of matriarchal phylogeny. Evolution 46:86j-881

Carr A, Goodman D (1970) Ecological implications of size and growth in Chelonia. Copela 1970:783-786

Chaloupka MY, Limpus CJ (1996a) Robust statistical modelling of Chelonia mydas growth rates-southern Great Barrier Reef. In: Keinath JA, Barnard DE, Musick JA, Bell BA (compulers) Proceedings of the Fifteenth Annual Symposium on Sea Turtle Biology and Conservation. NOAA Tech Memo NMFS-SIIISC-387:62-65

Chaloupka MY, Limpus CJ (1996b) Heuristic modelling of Chelonia mydas population dynamics - southern Great Barrier Reef. In: Keinath JA, Barnard DE, Musick JA, Bell BA (compilers) Proceedings of the Fifteenth Annual Symposium on Sea Turtle Biology and Conservation. NOAA Tech Memo NMFS-SEFSC-387:66-69

Chaloupka MY, Limpus CJ (1997) Robust statistical modelling of hawksbill sea turtle growth rates (southern Great Barrer Reef). Mar Ecol Prog Ser 146:1-8

Chaloupka MY, Musick JA (1997) Age, growth and population dynamics. In: Lutz PJ, Musick JA (eds) The biology of sea turtles, Chap 9. CRC Marine Science Series, CRC Press lnc, Boca Raton, p 235-278

Cleveland WS (1993) Visualizing data. Hobart Press, Summit $\mathrm{NJ}$

Collazo JA, Boulon RH, Tallevast TL (1992) Abundance and growth patterns of Chelonia mydas in Culebra, Puerto Rico. J Herpetol 26:293-300

Draper NR, Smith H (1981) Applied regression analysis, 2nd edn. John Wiley and Sons, New York

Ehrhardt NM, Witham R (1992) Analysis of growth of the green sea turtle (Chelonia mydas) in the western central Atlantic. Bull Mar Sci 50:275-281

Frazer NB, Ehrhart LM (1985) Preliminary growth models for green, Chelonia mydas, and loggerhead, Caretta caretta, turtles in the wild. Copeia 1985:73-79

Frazier $J(1980)$ Exploitation of marine turtles in the Indian Ocean. Human Ecol 8:329-370

Gerald CF, Wheatley PO (1994) Applied numerical analysis, 5th edn. Addison-Wesley Publishing Company, Reading, MA

Godinez-Domınguez E, Carretero-Montes RE, Silva-Batiz Fde.A, Ruiz S, Aguilar B (1993) Crecimiento de neonatos de Chelonia agassizii (Testudines: Chelonıdae) en cautiverio. Rev Biol Trop 41:253-260

Green D (1993) Growth rates of wild immature green turtles in the Galapagos Islands, Ecuador. J Herpetol 27:338-341

Harris AN, Dews G, Bishop M. Pitcher C (1995) Transfer of traditional fisheries monitoring in Torres Strait to AFMA with training: annual estimate of the catch of dugong and turtle. TSISAC Rreport No. 23, April 1995, CSIRO Division of Fisheries, (leveland, Australia

Hastie TJ (1993) Generalized additive models. In: Chambers JM, Hastie TJ (cds) Statistical models in S, Chap 7. Chapman and Hall, New York, p 249-307

Hastie TJ, Tibshiranı RJ (1990) Generalized additive models. Monographs on statistics and applied probability, 43. Chapman and Hall, London

Hirth HF, Rohovit DL (1992) Marketing patterns of green and hawksbill turtles in Port Moresby, Papua New Guinea. Oryx 26:39-42 
Horikoshi K, Suganuma $H$, Tachikawa $H$, Sato F, Yamaguchi M (1994) Decline of Ogasawara green turtle population in Japan. In: Bjorndal KA, Bolten AB, Johnson DA, Eliazar PJ (eds) Proceedings of the Fourteenth Annual Symposium on Sea Turtle Biology and Conservation. NOAA Tech Memo NMFS-SEFSC-351:235-237

Limpus CJ (1992) The hawksbill turtle, Eretmochelys imbricata, in Queensland: population structure within a southern Great Barrier Reef feeding ground. Wildl Res 19: 489-506

Limpus CJ (1993a) The worldwide status of marine turtle conservation. In: Nacu A, Trono R, Palma JA, Torres D, Agas $F$ (eds) Proceedings of the First ASEAN SymposiumWorkshop on Marine Turtle Conservation. World Wildlife Fund, Manila, p 43-61

Limpus CJ (1993b) The green turtle, Chelonia mydas, in Queensland: breeding males in the southern Great Barrier Reef. Wildl Res 20:513-523

Limpus CJ (1994) Current declines in southeast Asian turtle populations. In: Schroeder BA, Witherington BE (eds) Proceedings of the Thirteenth Annual Symposium on Sea Turtle Biology and Conservation. NOAA Tech Memo NMFS-SEFSC-341:89-91

Limpus CJ, Couper PJ, Read MA (1994) The green turtle, Chelonia mydas, in Queensland: population structure in a warm temperate feeding area. Mem Queensland Mus 35: $139-154$

Limpus CJ, Miller JD, Parmenter CJ, Reimer D, McLachlan N, Webb R (1992) Migration of green (Chelonia mydas) and loggerhead (Caretta caretta) turtles to and from eastern Australian rookeries. Wild! Res 19:347-358

Limpus CJ, Nicholls N (1994) Progress report on the study of the interaction of the El Niño-Southern Oscillation on annual Chelonia mydas at the southern Great Barrier Reef rookeries. In: James $R$ (ed) Proceedings of the Marine Turtle Conservation Workshop. Australian National Parks

This article was submitted to the editor and Wildlife Service, Canberra, p 73-78

Limpus CJ, Reed PC (1985) The green turtle, Chelonia mydas, in Queensland: a preliminary description of the population structure in a coral reef feeding ground. In: Grigg $G$, Shine R, Ehmann $\mathrm{H}$ (eds) Biology of Australasian frogs and reptiles. Royal Society of New South Wales, Sydney, p $47-52$

McCullagh P, Nelder JA (1989) Generalized linear models, 2nd edn. Monographs on statistics and applied probability, 37. Chapman and Hall, London

Mortimer JA (1992) Marine turtle conservation in Malaysia Malayan Nat J 45:353-361

National Research Council (1990) Decline of sea turtles: causes and prevention. National Academy Press, Washington, DC

Nietschmann B (1979) Ecological change, inflation, and migration in the far western Caribbean. Geogr Rev 69: $1-24$

Norman JA, Moritz C, Limpus CJ (1994) Mitochondrial DNA. control region polymorphisms: genetic markers for ecological studies of marine turtles. Molec Ecol 3:363-373

Parsons JJ (1962) The green turtle and man. University of Florida Press, Gainesville

Poiner IR, Harris ANM (1996) The incidental capture, direct mortality and delayed mortality of turtles in Australia's northern prawn fishery. Mar Biol 125:813-825

Ramsay J (1988) Monotone splines in action (with discussion). Statist Sci 3:425-461

van Buskirk J, Crowder LB (1994) Life-history variation in marine turtles. Copeia 1994:66-81

Wang $B$ (1995) Interdecadal changes in El Niño onset in the last four decades. J Clim 8: 267-285

Zug GR, Wynn AH, Ruckdeschel C (1986) Age determination of loggerhead sea turtles, Caretta caretta, by incremental growth marks in the skeleton. Smithsonian Contrib Zool $427: 1-34$

Manuscript first received: September 24, 1996

Revised version accepted: February 7, 1997 